\title{
Curative Role of D-Penicillamine versus Combined Garlic and Silymarin Extracts on Lead-Induced Nephrotoxicity and Oxidative Stress in Adult Male Albino Rats
}

\author{
Amal Mohamad Abd Elkhalek and Nermien A. Ibrahim ${ }^{1}$
}

${ }^{1}$ Department of Forensic Medicine \& Clinical Toxicology, Faculty of Medicine, Zagazig University, Al Sharqia, Egypt.

\begin{abstract}
Background Lead $(\mathrm{Pb})$ poisoning is still an important global health problem, especially in developing countries. Lead has been extensively used for many years ago, and it will continue to be used in future. Aim of work: This study was conducted to compare the curative role of D-penicillamine versus combined garlic and silymarin extracts for treating nephrotoxicity in adult male rats exposed to $\mathrm{Pb}$ for 3 months. Material and methods: The study was conducted on 70 adult male albino rats divided into 7 groups each of 10 rats, where they received all chemicals by oral gavage. Groups I \& II were the negative and positive control rats, respectively. Group III received $25 \mathrm{mg} / \mathrm{kg} /$ day D-penicillamine for 1 month ( $4^{\text {th }}$ month). Group IV received combined garlic $20 \mathrm{mg} / \mathrm{kg} /$ day+ silymarin $200 \mathrm{mg} / \mathrm{kg} /$ day for 1 month $\left(4^{\text {th }}\right.$ month). Group V received $20 \mathrm{mg} / \mathrm{kg} /$ day $\mathrm{Pb}$ acetate for 3 months. Group VI received $\mathrm{Pb}$ acetate for 3 months followed by D-penicillamine for another 1 month, with the previously mentioned doses. Group VII received $\mathrm{Pb}$ acetate for 3 months followed by combined garlic \& silymarin for another 1 month, with the previously mentioned doses. At the end of the experimental period (4 months), Pb-level in blood, urine \& kidney tissue, kidney function tests (blood urea and serum creatinine) and serum malondialdehyde (MDA) \& glutathione peroxidase (GSH-Px) were measured. Light microscopic examination of hematoxylin and eosin stained kidney tissue was performed to detect histopathological changes. Results: Lead administration significantly elevated blood lead level (BLL), kidney lead level (KLL), urinary lead level (ULL) and malondialdehyde (MDA), while glutathione peroxidase (GSH-Px) showed significant decrease when compared with the negative control rats. In $\mathrm{Pb}$ treated group, histopathological examination of the kidney revealed extensive tubular damage by presence of necrotic epithelial cells, tubular degeneration, necrosis, cell swelling, mononuclear cell infiltration, and degenerated organelles. Kidney functions didn't show any significant differences among all groups. Treatment of rats by D-penicillamine or combined garlic \& silymarin extracts resulted in significant decrease in Pb-levels and MDA with a significant increase in blood GSH-PX levels. Also, significant improvement of lead induced histopathological lesions in the kidneys was observed. Combined garlic and silymarin extract treatment showed more significant improvement than $\mathrm{D}$-penicillamine treated $\mathrm{Pb}$-administered groups, in most of the tested parameters. Conclusion: Both D-penicillamine and combined garlic \& silymarin extracts can reduce lead induced nephrotoxicity and oxidative stress. Moreover, garlic \& silymarin curative effect is better than that of D-penicillamine. Recommendations: Exposure of the population to lead must be controlled. Search for sensitive blood or urinary marker for early detection of kidney damage and further studies are needed to consider a combination of garlic and silymarin is effective in the treatment of lead-induced toxicities.
\end{abstract}

Keywords Lead, D-penicillamine, garlic, silymarin, kidney.

\section{Introduction}

$\mathrm{L}$ ead $(\mathrm{Pb})$ has been in use by human population for the past 5000 years. During this period lead production has been said to have increased from a mere 10 tons per annum to a staggering 1 million tons per year, a phenomenon that has accompanied industrial progress (Brown and Margolis, 2012). As a highly toxic heavy metal, the pollution and exposure risks of lead are of widespread concern for human health. It is well-documented to be one of the most dangerous and insidious poisons affecting humans and animals of all ages (Cao et al., 2015; Behmke et al., 2015; Godwill et al., 2015). A safe level of lead exposure has not been defined and it is widely accepted that even small quantities are harmful to human and other organisms (Mielke et al., 2013). 
Nowadays, although the vast majority of its uses have disappeared, $\mathrm{Pb}$ is still present in many industrial activities such as car repair, manufacturing and recycling of batteries, lead paint removal, demolition, refining and smelter. Moreover it is used for maintenance of structures found in the open air as bridges or water towers, in solders of cans of food or beverages, glazed ceramic, and can be present in drinking water or in tobacco smoke as well as leaded gasoline. In addition environmental pollution by lead is persistent and widespread, affecting the population (AlRudainy, 2010; García-Lestón et al., 2010; Bi et al., 2015; Piadé et al., 2015). Lead content in lipstick and other consumer products has become an increasing concern. In 2010, the United States Food and Drug Administration tested 400 lipstick samples and found a maximum $\mathrm{Pb}$ concentration of 7.19 part per million, which constitutes great risk for adults that chronically apply lipstick as well as instances where children might incidentally ingest lipstick products (Monnot et al., 2015).

The exposure routes for $\mathrm{Pb}$ are, mainly, through inhalation and ingestion, where adults absorb approximately $10 \%$ of ingested $\mathrm{Pb}$ through the gastrointestinal tract. Once absorbed, $\mathrm{Pb}$ is found in all tissues, but $90 \%$ of the load is deposited in bone, where it accumulates over the carrier's lifetime and can act as an endogenous source of the metal (Padiha et al., 2011; Boisa et al., 2014).

It is well documented that lead can cause deleterious effects on the reproductive, haematological and cardiovascular systems, neurotoxicity, nephrotoxicity, genotoxicity and embryotoxicity in laboratory animals and humans (Anjum et al., 2011; Kayaalti et al., 2015; Skerfving et al., 2015; Szymańska-Chabowska et al., 2015). Lead exposure is an established cause of chronic kidney disease in adults and children, where adverse associations between blood $\mathrm{Pb}$ and kidney function have been observed (lee \& Kim, 2012).

Current treatment of $\mathrm{Pb}$ poisoning includes the use of chelating agents (Padiha et al., 2011). Penicillamine, a sulfhydryl containing amino-acid and a degradation product of penicillin, is a pharmaceutical chelating agent, where the D-isomer is used mainly as a chelating agent in heavy metal toxicity including $\mathrm{Pb}$, mercury and copper poisoning (Flora and Pachauri, 2010).

Although several chelating agents have been shown to reduce $\mathrm{Pb}$ toxicity, some of them are burdened with undesirable side effects (Aaseth et al., 2015). Accordingly, $\mathrm{Pb}$ intoxication therapy is looking for the development of new therapeutic agents with different modes of action especially from the medicinal plants (Gargouri et al., 2013).

Recent studies have demonstrated and validated many medicinal properties attributed to garlic. Different types of garlic supplements like garlic powder (tablets), garlic extracts (capsules, tablets and liquid) and garlic oil (capsule) is commercially available; each being different in organosulfur compound profile. Extensive studies carried out on garlic have described the presence of two main classes of antioxidant machineries, namely flavonoids and sulfur-containing compounds as diallyl sulfide, trisulfide and allyl-cysteine (Zaidi et al., 2015). These are likely to play an important role in the widely demonstrated biological effects of garlic, which include antitumor, hypolipidemic, hypocholesterolemic, antiatherosclerotic, antioxidant and immunomodulatory effects (Schäfer and Kaschula, 2014; Mohammadi and Oshaghi, 2014)

Silymarin is a polyphenolic flavonoid derived from milk thistle (Silybum marianum). It contains a mixture of four flavonolignan isomers: silibinin (70$80 \%)$, silycristin (20\%), silydianin (10\%), and isosilybin $(0.5 \%)$. Silibinin is therefore the major active constituent of silymarin and is responsible for its pharmacological activity. The results of several studies using animal models showed that Silymarin has antiinflammatory, cytoprotective, neuroprotective and anticarcinogenic effects that suppress production of reactive oxygen species (ROS) and lipid peroxidation in blood and liver (Jain et al., 2011; Vaid et al., 2013; Oliveira et al., 2015; Yang et al., 2015).

The aim of the present study is to compare the curative role of D- penicillamine versus combined garlic and silymarin extracts on the nephrotoxic effects and oxidative stress of sub-chronic $\mathrm{Pb}$ administration in adult male albino rats.

\section{Material and methods}

This study is a part of a research project funded by the Project Management of Zagazig University.

\section{I-Material}

- Chemicals

1) Lead-acetate $[(\mathrm{C} 2 \mathrm{H} 3 \mathrm{O} 2) 2 \mathrm{~Pb}$ : Lead acetate in the form of white crystals manufactured by El Nasr Pharmaceutical Chemical Company.

2) D-Penicillamine: in the form of white crystalline powder obtained from SigmaAldrich Chemical Co.

3) Aqueous garlic extract (AGE): was prepared at department of Pharmacognesy Faculty of Pharmacy- Zagazig University.

4) Silymarin crude material: was prepared from the milk thistle plant at the Department of Pharmacognesy, Faculty of Pharmacy, Zagazig University.

\section{- Animals}

Seventy adult male albino rats, of average weight between 180-200 gm, were obtained from the animal house of Faculty of Medicine, Zagazig University. Before commencing experimentation, the animals were subjected to 7 days period of acclimatization to be adapted to environment, to ascertain their physical well being and to exclude diseased animals. Food was offered in equal amounts to all rats in each cage and water was offered adlibitum in separate clean containers. 
- $\quad$ Ethical considerations of the study

The study was conducted according to the guide for care and use of laboratory animals.

All ethically approved considerations for animal housing and handling were considered.

The experimental protocol used followed the regulations for administration and for painless scarification of the experimental animals.

The animals were acclimated in the animal house before the start of the study.

\section{- Kits}

Bio-diagnostic kits for estimation of Pb-level, blood urea, serum creatinine, serum malondialdehyde (MDA) and glutathione peroxidase (GSH-Px) were used.

\section{II- Methods}

\section{1) Extraction of garlic (Figure-1)}

Garlic extract was prepared by homogenizing the required amount of garlic cloves in an appropriate volume of distilled water to prepare a concentration of $20 \mathrm{mg} / \mathrm{ml}$. The homogenate was centrifuged at $3000 \mathrm{x} \mathrm{g}$ for 10 minutes to remove particulate matter and the supernatant fraction was used for the experiment (Shaarawy et al., 2009).

2) Extraction of crude silymarin (Figure-1)

Silybum marianum was extracted as described by Polyak et al. (2007). Briefly, fine powder of seeds was made in a blender. The seed powder were defatted in $n$-hexane 2-3 times and extracted with aqueous acetone. The extract was concentrated to remove acetone by using a rotary evaporator, and then washed by hexane again to remove hydrophobic impurities. The remaining concentrate was treated by $1 \% \mathrm{NaCl}$ solution to remove water soluble impurities. The precipitate and solid obtained through drying were combined together to form crude silymarin. The crude silymarin was washed with aqueous ethanol and then dried completely to give the refined silymarin.

\section{3) Experimental design}

The rats were randomly divided into 7 groups each of 10 rats, where they received all treatments through oral gavage for 6 days/week:

\section{- $\quad$ Group I (negative control group)}

Kept on normal diet and water for 4 months and used to estimate basic parameters.

- $\quad$ Group II (positive control group):

Received $1 \mathrm{ml}$ saline/rat/day for 4 months.

- $\quad$ Group III (D-penicillamine group)

Received $1 \mathrm{ml}$ saline/rat/day for 3 months, then D-penicillamine in a dose of $25 \mathrm{mg} / \mathrm{kg}$ dissolved in $1 \mathrm{ml}$ saline for 1 month. Dpenicillamine is administrated on empty stomach, then no meals are given unless passage of 1 hour after administration (Golalipour et al., 2007).

- Group IV (combined garlic+ silymarin group)
Received $1 \mathrm{ml}$ saline/rat/day for 3 months, then a combination of $20 \mathrm{mg} / \mathrm{Kg} /$ day of garlic (Shaarawy et al., 2009) and $200 \mathrm{mg} / \mathrm{kg} /$ day of silymarin (Soto et al., 2010) dissolved in $1 \mathrm{ml}$ saline for 1 month.

- $\quad$ Group V ( $\mathrm{Pb}$ acetate group)

Received $1 \mathrm{ml}$ saline/day for 1 month then, received $20 \mathrm{mg} / \mathrm{kg} /$ day lead acetate (Instito' ris et al., 1999) dissolved in $1 \mathrm{ml}$ saline, for 3 months.

- Group VI (Pb acetate + D-penicillamine group)

Each rat received $\mathrm{Pb}$ acetate for 3 months followed by D-penicillamine for another 1 month, with the previously mentioned doses.

Group VII $(\mathrm{Pb}$ acetate + combined garlic \& silymarin group)

Each rat received $\mathrm{Pb}$ acetate for 3 months followed by combined garlic \& silymarin for another 1 month, with the previously mentioned doses.

4) Urine Collection (Figure-2):

At the end of the study (4 months) the animals were housed individually for 24 hours in metabolic cages and allowed to access water. Urine sample was collected from each rat by means of these metabolic cages (Kurien et al., 2004) enough cages were prepared.

\section{5) Blood collection:}

After urine collection, a volume of $2 \mathrm{ml}$ venous blood samples were obtained from the retroorbital plexus of anaesthetized animals (Johnson, 2007). These blood samples are collected in glass tubes, allowed to clot then centrifuged to collect the clear sera to perform all blood-related biochemical analysis.

6) Kidney sampling:

After blood collection the rats were sacrificed, both kidneys of each rat were divided into 2 parts, one part weighed $1 \mathrm{gm}$ was wrapped with aluminum foil and embedded in liquid nitrogen for 1 hour then kept frozen in $-80^{\circ} \mathrm{C}$ till used to asses lead concentration in kidney (Miller et al., 1987). The $2^{\text {nd }}$ part was fixed in formalin $10 \%$ solution for histopathological examination after staining with haematoxyline and eosin (H\&E) according to Bancroft and Stevens (2002).

\section{7) Biochemical Studies:}

a) Estimation of Lead Levels

Lead was estimated in the blood (BLLs), urine (ULLs) $(\mu \mathrm{g} / \mathrm{dL})$ and kidney tissues (KLLs) $(\mu \mathrm{g} / \mathrm{gm}$ tissue $)$ by graphite furnace atomic absorption spectrophotometry (Model 210 VGP, Buck Scientific USA) at the Central Laboratory, Faculty of Veterinary Medicine, Zagazig University, Lead loads were estimated at $217 \mathrm{~nm}$ wavelength, which was generated, from a lead cathode lamp, following the instrument's manual instruction according to 
the method described by (Miller et al., 1987; AOAC, 1990).

\section{b) Kidney function tests}

Blood urea and serum creatinine were determined using the method proposed by Henry (1974).

c) Assessment of Blood Oxidative Stress:

I. Erythrocyte malondialdehyde (MDA) in blood

Lipid peroxidation was measured by estimating serum MDA according to the method proposed by Yoshioka et al. (1979).

II. Blood glutathione peroxidase (GSHPx)

Glutathione peroxidase (GSH-Px) enzyme was determined in blood according to the method proposed by Pleban et al. (1982).

\section{8) Statistical analysis}

SPSS Software program was used. Mean values $(\mathrm{X}) \pm$ Standard Deviation (SD) were calculated, Analysis of variance (ANOVA or F test), least significant difference (LSD) and Z-test for two samples proportion were performed. Differences were considered significant when P-value is less than 0.05.

\section{Results}

\section{Death rate}

Two rats died in group V, one rat in group VI and one rat in group VII.

\section{Biochemical Results}

No significant differences ( $p>0.05)$ were detected in all tested biochemical parameters among negative control (group I), positive control (group II), penicillaminetreated group (group III) and combined garlic \& silymarin treated group (group IV) (table-1).

a) Lead Levels (Tables-2,3,4 \&5)

For BLL, ULL \& KLL, Significant elevations $(\mathrm{p}<0.05)$ were detected in all mean values of $\mathrm{Pb}$ treated group (group V), D-penicillamine treated group after $\mathrm{Pb}$ (group VI) and combined garlic \& silymarin treated group after $\mathrm{Pb}$ (group VII) when compared to negative control group (group I).

For BLL \& KLL mean values, groups VI \& VII showed significant decrease $(p<0.05)$ compared to the corresponding value in groups $\mathrm{V}$. Also, group VII showed significant decrease $(\mathrm{p}<0.05)$ in comparison with group VI.

For ULL mean values, groups VI \& VII showed significant increase $(\mathrm{p}<0.05)$ compared to the corresponding value in group V. Moreover, group VII showed significant increase $(\mathrm{p}<0.05)$ in comparison with group VI.

b) Kidney Function Tests (Table-2)

No significant changes $(\mathrm{P}>0.05)$ were detected in the mean levels of blood urea $\&$ serum creatinine of groups V, VI and VII when compared to group I.

c) Blood Oxidative Stress:

i. Erythrocyte malondialdehyde (MDA) in blood (Tables-2 \& 6)

Significant elevations $(\mathrm{p}<0.05)$ were detected in the mean MDA levels of group $\mathrm{V}$ and group VI compared to groups I and VII. Also, Significant elevation $(\mathrm{p}<0.05)$ was detected in the mean MDA levels of group V compared to group VI.

Non-significant change ( $p>0.05)$ was detected in the mean MDA level of group VII when compared to the control group I.

ii. Blood glutathione peroxidase (GSH-Px), Tables( 2\&7)

Significant decreases $(\mathrm{p}<0.05)$ were detected in the mean GSH-Px levels of groups V, VI and VII compared to group I.

Significant increase $(\mathrm{p}<0.05)$ was detected in GSH-Px mean levels of groups VI \& VII when compared to group V. However, non-significant change $(\mathrm{p}>0.05)$ was detected in GSH-Px mean level of group VII when compared to group VI.

Histopathological Results (Tables-8,9 \&10)

Examination of H\&E stained kidney sections of groups I, II, III and IV showed normal renal corpuscles consisting of Bowman's capsule with an outer covering layer of simple squamous epithelium and an inner wall formed of flattened epithelial cells. The glomerulus enclosed within the Bowman's capsule showed normal architectural pattern and the proximal convoluted tubules were numerous with round outlines (Figures-3 $a, b \& c)$.

In group $\mathrm{V}, \mathrm{Pb}$ treatment caused extensive tubular damage, different degrees of cloudy swelling of epithelial cells of renal tubules, cell swelling and vaculation, necrosis, mononuclear cell infiltration, congestion, homogenous acidophilic materials and contraction of the glomeruli with expansion of Bowman's space (Figure-3 d, e \& f). All mentioned pathological changes when statistically analyzed by Ztest, showed significant increase in comparison with the control group.

In group $\mathrm{VI}$, treatment of $\mathrm{Pb}$-administered rats with D-penicillamine displayed relieve of the renal pathological changes caused by lead except for congestion and moderate degree of inflammatory cells infiltration (Figure-3 g), which showed significant increase compared to the control group and group VII but showed non-significant change when compared with group $\mathrm{V}$.

In group VII, treatment of $\mathrm{Pb}$-administered rats with combined garlic \& silymarin improved the histopathological changes which were observed in the lead treated group but, displayed mild degree of congestion which showed non-significant change when compared to control group, group $\mathrm{V}$ and group VI (Figure-3 h). 
Table-1: One way ANOVA for statistical comparison of BLL, KLL, ULL, blood urea, serum creatinine, MDA and GSH-Px among negative control (Group I), positive control (Group II), D-penicillamine treated (Group III) and combined garlic \& silymarin treated group (Group IV) during the whole period of the study.

\begin{tabular}{|c|c|c|c|c|c|c|}
\hline Groups & I & II & III & IV & \multirow[b]{2}{*}{$F$} & \multirow[b]{2}{*}{$\mathbf{P}$} \\
\hline & $\begin{array}{c}(\mathbf{M} \pm \text { SD }) \\
n=10\end{array}$ & $\begin{array}{c}(\mathbf{M} \pm \text { SD }) \\
\mathrm{n}=10\end{array}$ & $\begin{array}{c}(\mathrm{M} \pm \mathrm{SD}) \\
\mathrm{n}=10\end{array}$ & $\begin{array}{c}(\mathrm{M} \pm \mathrm{SD}) \\
\mathrm{n}=10\end{array}$ & & \\
\hline BLL $\mu \mathrm{g} / \mathrm{dL}$ & $11.8 \pm 1.2$ & $11.9 \pm 1.3$ & $10.61 \pm 1.94$ & $9.98 \pm 2.65$ & 2.512 & 0.074 \\
\hline KLL $\mu \mathrm{g} / \mathrm{gm}$ tissue & $0.891 \pm 0.041$ & $0.887 \pm 0.049$ & $0.884 \pm 0.050$ & $0.856 \pm .088$ & 0.708 & 0.553 \\
\hline ULL $\mu \mathrm{g} / \mathrm{dL}$ & $0.51 \pm 0.15$ & $0.48 \pm 0.14$ & $0.46 \pm 0.28$ & $0.53 \pm 0.24$ & 0.217 & 0.884 \\
\hline Blood urea & $27.21 \pm 3.28$ & $27.14 \pm 3.281$ & $26.79 \pm 2.597$ & $27.26 \pm 3.17$ & 0.047 & 0.986 \\
\hline Serum creatinine & $0.931 \pm 0.211$ & $0.955 \pm 0.193$ & $0.944 \pm 0.184$ & $0.946 \pm 0.207$ & 0.025 & 0.995 \\
\hline MDA $\mu \mathrm{mol} / \mathrm{L}$ & $0.491 \pm 0.053$ & $0.464 \pm 0.042$ & $0.496 \pm 0.049$ & $0.461 \pm 0.05$ & 1.279 & 0.296 \\
\hline GSH-Px U/L & $0.484 \pm 0.047$ & $0.464 \pm 0.042$ & $0.481 \pm 0.045$ & $0.514 \pm 0.05$ & 2.035 & 0.126 \\
\hline
\end{tabular}

M: mean value, SD: standard deviation, $n$ : number of rats in each group.

Table-2: One way ANOVA for statistical comparison of BLL, KLL, ULL, blood urea, serum creatinine, MDA and GSH-Px among negative control (Group I), lead treated group (Group V), lead + D-penicillamine treated (Group VI) and lead + combined garlic \& silymarin treated group (Group VII) during the whole period of the study.

\begin{tabular}{|c|c|c|c|c|c|c|}
\hline Groups & $\mathbf{I}$ & $\mathbf{V}$ & VI & VII & \multirow[b]{2}{*}{$\mathbf{F}$} & \multirow[b]{2}{*}{$\mathbf{P}$} \\
\hline & $\begin{array}{c}(\mathrm{M} \pm \mathrm{SD}) \\
\mathrm{n}=10\end{array}$ & $\begin{array}{c}(\mathrm{M} \pm \mathrm{SD}) \\
\mathrm{n}=8\end{array}$ & $\begin{array}{c}(\mathrm{M} \pm \mathrm{SD}) \\
\mathrm{n}=9\end{array}$ & $\begin{array}{c}(\mathrm{M} \pm \mathrm{SD}) \\
\mathrm{n}=9\end{array}$ & & \\
\hline BLL $\mu \mathrm{g} / \mathrm{dL}$ & $11.8 \pm 1.2$ & $111.3 \pm 11.14$ & $29.51 \pm 7.4$ & $21.14 \pm 3.6$ & 395.647 & $0.000 *$ \\
\hline KLL $\mu \mathrm{g} / \mathrm{gm}$ tissue & $0.891 \pm 0.041$ & $21.45 \pm 3.858$ & $11.15 \pm 2.185$ & $8.869 \pm 1.748$ & 121.597 & $0.000 *$ \\
\hline ULL $\mu \mathrm{g} / \mathrm{dL}$ & $0.51 \pm 0.15$ & $19.53 \pm 4.35$ & $46.12 \pm 9.68$ & $67.18 \pm 10.66$ & 143.324 & $0.000 *$ \\
\hline Blood urea & $27.21 \pm 3.28$ & $29.95 \pm 3.122$ & $30.34 \pm 3.173$ & $30.08 \pm 3.611$ & 1.898 & 0.150 \\
\hline Serum creatinine & $0.931 \pm 0.211$ & $0.941 \pm 0.19$ & $0.919 \pm 0.18$ & $1.028 \pm 0.3$ & 0.432 & 0.731 \\
\hline $\mathrm{MDA} \mu \mathrm{mol} / \mathrm{L}$ & $0.491 \pm 0.053$ & $2.011 \pm 0.412$ & $0.748 \pm 0.041$ & $0.485 \pm 0.057$ & 113.251 & $0.000^{*}$ \\
\hline GSH-Px U/L & $0.484 \pm 0.047$ & $0.190 \pm 0.04$ & $0.391 \pm 0.11$ & $0.363 \pm 0.07$ & 24.901 & $0.000 *$ \\
\hline
\end{tabular}

M: mean value, SD: standard deviation, $n$ : number of rats in each group, *: significant change $p<0.05$.

Table-3: Least significant difference among negative control (Group I), lead treated group (Group V), lead + Dpenicillamine treated (Group VI) and lead + combined garlic \& silymarin treated group (Group VII) regarding BLL.

\begin{tabular}{|l|c|c|c|c|}
\hline \multirow{3}{*}{ Groups } & $\mathbf{I}$ & $\mathbf{V}$ & $\mathbf{V I}$ & $\mathbf{V I I}$ \\
\cline { 2 - 5 } & $\begin{array}{c}\mathbf{M} \pm \mathbf{S D}) \\
\mathbf{n = 1 0}\end{array}$ & $\begin{array}{c}\mathbf{M} \pm \mathbf{S D}) \\
\mathbf{n = 8}\end{array}$ & $\begin{array}{c}\mathbf{( M \pm S D )} \\
\mathbf{n = 9}\end{array}$ & $\begin{array}{c}\mathbf{M} \pm \mathbf{S D}) \\
\mathbf{n = 9}\end{array}$ \\
\hline & $11.8 \pm 1.2$ & $111.3 \pm 11.14$ & $29.51 \pm 7.4$ & $21.14 \pm 3.6$ \\
\hline $\mathrm{I}$ & - & $0.000^{*}$ & $0.000^{*}$ & $0.000^{*}$ \\
\hline V & & - & $0.000^{*}$ & $0.000^{*}$ \\
\hline VI & & & - & $0.0076^{*}$ \\
\hline
\end{tabular}

M: mean value, SD: standard deviation, $n:$ number of rats in each group, *: significant change $p \nless 0.05$.

Table-4: Least significant difference among negative control (Group I), lead treated group (Group V), lead + Dpenicillamine treated (Group VI) and lead + combined garlic \& silymarin treated group (Group VII) regarding KLL.

\begin{tabular}{|l|c|c|c|c|}
\hline \multirow{3}{*}{ Groups } & $\mathbf{I}$ & $\mathbf{V}$ & $\mathbf{V I}$ & VII \\
\cline { 2 - 5 } & $\begin{array}{c}\mathbf{M} \pm \mathbf{S D}) \\
\mathbf{n = 1 0}\end{array}$ & $\begin{array}{c}\mathbf{M} \pm \mathbf{S D}) \\
\mathbf{n = 8}\end{array}$ & $\begin{array}{c}\mathbf{M} \pm \mathbf{S D}) \\
\mathbf{n = 9}\end{array}$ & $\begin{array}{c}\mathbf{M} \pm \mathbf{S D}) \\
\mathbf{n}=\mathbf{9}\end{array}$ \\
\hline & $0.891 \pm 0.041$ & $21.45 \pm 3.858$ & $11.15 \pm 2.185$ & $8.869 \pm 1.748$ \\
\hline $\mathrm{I}$ & - & $0.000^{*}$ & $0.000^{*}$ & $0.000^{*}$ \\
\hline $\mathrm{V}$ & & - & $0.000^{*}$ & $0.000^{*}$ \\
\hline $\mathrm{VI}$ & & & - & $0.0267^{*}$ \\
\hline
\end{tabular}

M: mean value, SD: standard deviation, $n:$ number of rats in each group, *: significant change $p<0.05$. 
Table-5: Least significant difference among negative control (Group I), lead treated group (Group V), lead + Dpenicillamine treated (Group VI) and lead + combined garlic \& silymarin treated group (Group VII) regarding ULL.

\begin{tabular}{|l|c|c|c|c|}
\hline \multirow{3}{*}{ Groups } & $\mathbf{I}$ & $\mathbf{V}$ & $\mathbf{V I}$ & $\mathbf{V I I}$ \\
\cline { 2 - 5 } & $\begin{array}{c}\mathbf{M} \pm \mathbf{S D}) \\
\mathbf{n}=\mathbf{1 0}\end{array}$ & $\begin{array}{c}\mathbf{M} \pm \mathbf{S D}) \\
\mathbf{n = 8}\end{array}$ & $\begin{array}{c}\mathbf{M} \pm \mathbf{S D}) \\
\mathbf{n = 9}\end{array}$ & $\begin{array}{c}\mathbf{M} \pm \mathbf{S D}) \\
\mathbf{n = 9}\end{array}$ \\
\hline & $0.51 \pm 0.15$ & $19.53 \pm 4.35$ & $46.12 \pm 9.68$ & $67.18 \pm 10.66$ \\
\hline $\mathrm{I}$ & - & $0.000^{*}$ & $0.000^{*}$ & $0.000^{*}$ \\
\hline $\mathrm{V}$ & & - & $0.000^{*}$ & $0.000^{*}$ \\
\hline VI & & & - & $0.0005^{*}$ \\
\hline
\end{tabular}

M: mean value, SD: standard deviation, $n:$ number of rats in each group, *: significant change $p \triangleleft 0.05$.

Table-6: Least significant difference among negative control (Group I), lead treated group (Group V), lead + Dpenicillamine treated (Group VI) and lead + combined garlic \& silymarin treated group (Group VII) regarding MDA level.

\begin{tabular}{|l|c|c|c|c|}
\hline \multirow{3}{*}{ Groups } & $\mathbf{I}$ & $\mathbf{V}$ & $\mathbf{V I}$ & $\mathbf{V I I}$ \\
\cline { 2 - 5 } & $\begin{array}{c}\mathbf{M} \pm \mathbf{S D}) \\
\mathbf{n = 1 0}\end{array}$ & $\begin{array}{c}\mathbf{M} \pm \mathbf{S D}) \\
\mathbf{n = 8}\end{array}$ & $\begin{array}{c}\mathbf{M} \pm \mathbf{S D}) \\
\mathbf{n = 9}\end{array}$ & $\begin{array}{c}\mathbf{M} \pm \mathbf{S D}) \\
\mathbf{n = 9}\end{array}$ \\
\hline & $0.491 \pm 0.053$ & $2.011 \pm 0.412$ & $0.748 \pm 0.041$ & $0.485 \pm 0.057$ \\
\hline $\mathrm{I}$ & - & $0.000^{*}$ & $0.000^{*}$ & 0.8149 \\
\hline $\mathrm{V}$ & & - & $0.000^{*}$ & $0.000^{*}$ \\
\hline $\mathrm{VI}$ & & & - & $0.000^{*}$ \\
\hline
\end{tabular}

M: mean value, SD: standard deviation, $n:$ number of rats in each group, *: significant change $p \nless 0.05$.

Table-7: Least significant difference among negative control (Group I), lead treated group (Group V), lead + Dpenicillamine treated (Group VI) and lead + combined garlic \& silymarin treated group (Group VII) regarding GSH-Px level.

\begin{tabular}{|l|c|c|c|c|}
\hline \multirow{3}{*}{ Groups } & $\mathbf{I}$ & $\mathbf{V}$ & $\mathbf{V I}$ & $\mathbf{V I I}$ \\
\cline { 2 - 5 } & $\begin{array}{c}\mathbf{M} \pm \mathbf{S D}) \\
\mathbf{n = 1 0}\end{array}$ & $\begin{array}{c}\mathbf{M} \pm \mathbf{S D}) \\
\mathbf{n = 8}\end{array}$ & $\begin{array}{c}\mathbf{M} \pm \mathbf{S D}) \\
\mathbf{n}=\mathbf{9}\end{array}$ & $\begin{array}{c}\mathbf{M} \pm \mathbf{S D}) \\
\mathbf{n = 9}\end{array}$ \\
\hline & $0.484 \pm 0.047$ & $0.190 \pm 0.04$ & $0.391 \pm 0.11$ & $0.363 \pm 0.07$ \\
\hline $\mathrm{I}$ & - & $0.000^{*}$ & $0.0258^{*}$ & $0.0003^{*}$ \\
\hline $\mathrm{V}$ & & - & $0.0002^{*}$ & $0.000^{*}$ \\
\hline $\mathrm{VI}$ & & & - & 0.5285 \\
\hline
\end{tabular}

M: mean value, SD: standard deviation, $n:$ number of rats in each group, *: significant change $p \varangle 0.05$.

Table-8: statistical Z-test for two samples proportion comparing histopathological changes of the kidney in lead treated group versus negative control group.

\begin{tabular}{|c|c|c|c|c|c|}
\hline \multirow{2}{*}{$\begin{array}{ll}\text { Pathology } & \text { Group } \\
\end{array}$} & \multirow{2}{*}{$\begin{array}{c}\text { I } \\
\text { N2/N1 }\end{array}$} & \multicolumn{2}{|r|}{$\mathbf{V}$} & \multirow{2}{*}{$Z$ value } & \multirow{2}{*}{$\mathbf{P}$} \\
\hline & & N2/ N1 & Proportion & & \\
\hline Cloudy swelling of tubular epith. & $0 / 10$ & $6 / 8$ & 0.75 & 3.3541 & $0.0008 *$ \\
\hline Cell vaculation & $0 / 10$ & $6 / 8$ & 0.75 & 3.3541 & $0.0008 *$ \\
\hline Cell necrosis & $0 / 10$ & $4 / 8$ & 0.50 & 3.5355 & $0.0118^{*}$ \\
\hline Mononuclear cell infiltration & $0 / 10$ & $7 / 8$ & 0.875 & 3.7839 & $0.0002 *$ \\
\hline Vascular congestion & $0 / 10$ & $7 / 8$ & 0.875 & 3.7839 & $0.0002 *$ \\
\hline Wide bowman's space & $0 / 10$ & $6 / 8$ & 0.75 & 3.3541 & $0.0008^{*}$ \\
\hline
\end{tabular}

N1: total number of rats in each group, N2: total number of rats in each group, *: significant change at p $<0.05$.

Table -9: statistical Z-test for two samples proportion comparing histopathological changes of the kidney in lead + D-penicillamine treated group (group VI) versus negative control group (group I).

\begin{tabular}{|c|c|c|c|c|c|}
\hline \multirow{2}{*}{ Pathology Group } & \multirow{2}{*}{ I } & \multicolumn{2}{|r|}{ VI } & \multirow{2}{*}{$Z$ value } & \multirow{2}{*}{$\mathbf{P}$} \\
\hline & & N2/ N1 & Proportion & & \\
\hline Cloudy swelling of tubular epith. & $0 / 10$ & $0 / 9$ & 0 & - & - \\
\hline Cell vaculation & $0 / 10$ & $0 / 9$ & 0 & - & - \\
\hline Cell necrosis & $0 / 10$ & $0 / 9$ & 0 & & \\
\hline Mononuclear cell infiltration & $0 / 10$ & $4 / 9$ & 0.444 & 2.3727 & $0.01778^{*}$ \\
\hline Vascular congestion & $0 / 10$ & $5 / 9$ & 0.5556 & 2.7458 & $0.00596^{*}$ \\
\hline Wide bowman's space & $0 / 10$ & $0 / 9$ & 0 & - & - \\
\hline
\end{tabular}

N1: total number of rats in each group, N2: total number of rats in each group, *: significant change at p $<0.05$. 
Table -10: statistical Z-test for two samples proportion comparing histopathological changes of the kidney in lead treated group (group V) versus lead + D-penicillamine treated group (group VI ).

\begin{tabular}{|l|l|l|l|l|l|l|}
\hline \multirow{2}{*}{ Pathology } & \multicolumn{2}{c|}{ Group } & \multicolumn{2}{c|}{ VI } & \multirow{2}{*}{ Z value } & \multirow{2}{*}{ P } \\
\cline { 2 - 6 } & $\mathbf{N 2 / N 1}$ & proportion & N2/ N1 & Proportion & & \\
\hline Cloudy swelling of tubular epith. & $6 / 8$ & 0.75 & $0 / 9$ & 0 & 3.2298 & $0.00124^{*}$ \\
\hline Cell vaculation & $6 / 8$ & 0.75 & $0 / 9$ & 0 & 3.2298 & $0.00124^{*}$ \\
\hline Cell necrosis & $4 / 8$ & 0.50 & $0 / 9$ & 0 & 2.4258 & $0.0151^{*}$ \\
\hline Mononuclear cell infiltration & $7 / 8$ & 0.875 & $4 / 9$ & 0.444 & 1.8542 & 0.0643 \\
\hline Vascular congestion & $7 / 8$ & 0.875 & $5 / 9$ & 0.556 & 1.4428 & 0.1499 \\
\hline Wide bowman's space & $6 / 8$ & 0.75 & $0 / 9$ & 0 & 3.2298 & $0.00124^{*}$ \\
\hline
\end{tabular}

N1: total number of rats in each group, N2: total number of rats in each group, *: significant change at $p<0.05$.

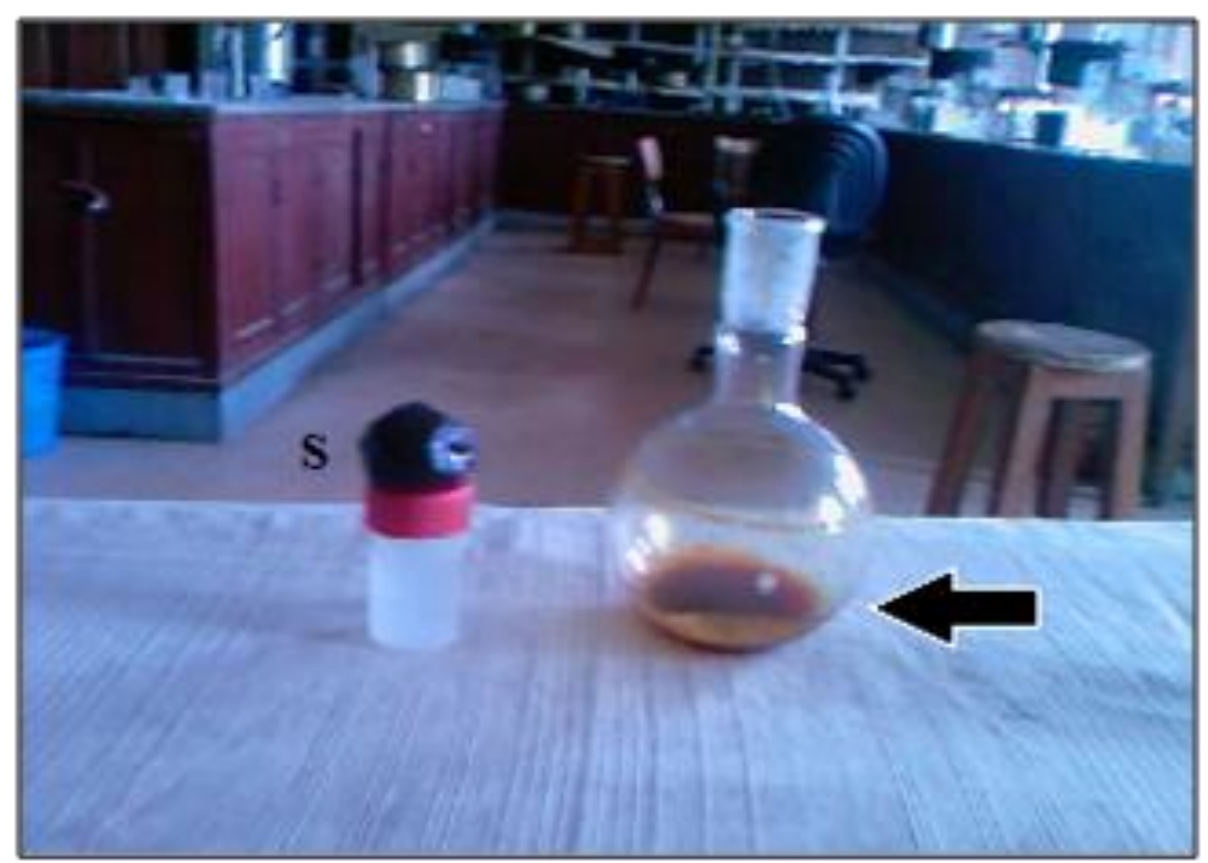

Figure (1) A photograph showing garlic extract (arrow) and silymarin crude material (S).

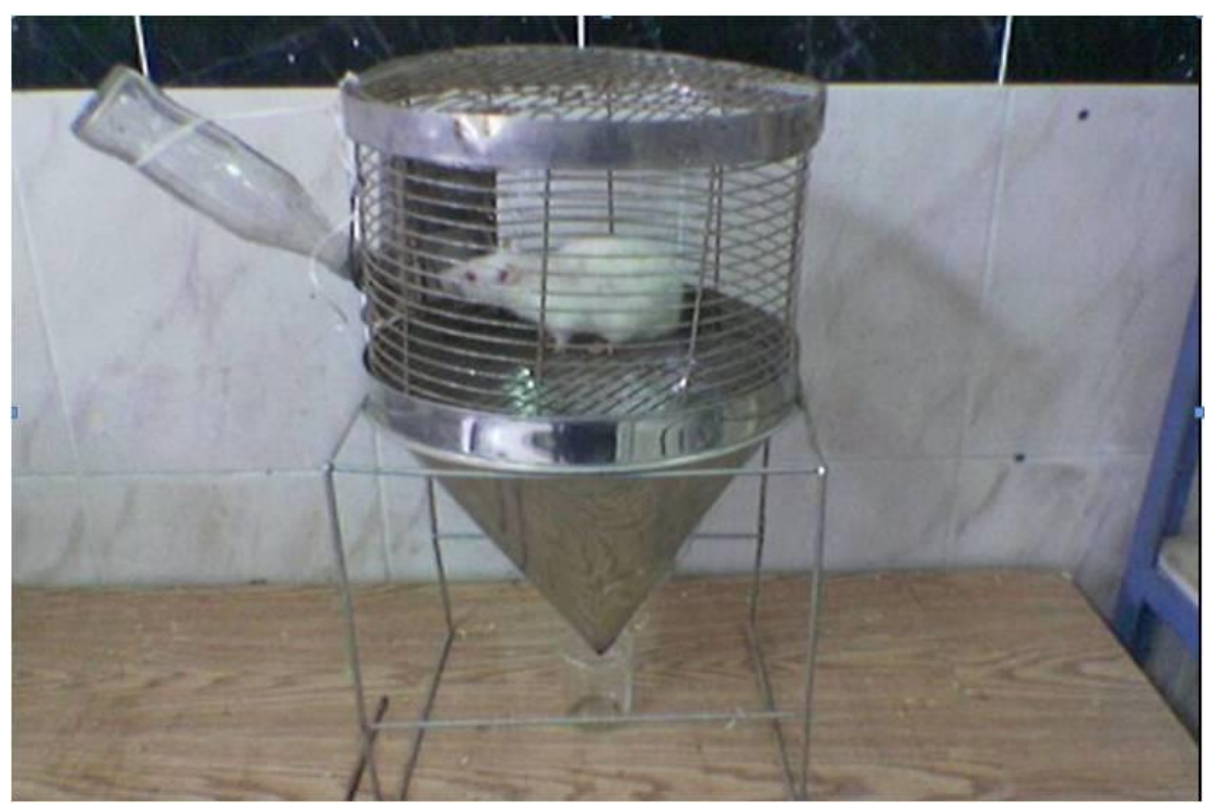

Figure (2) A photograph showing metabolic cage for urine collection. 

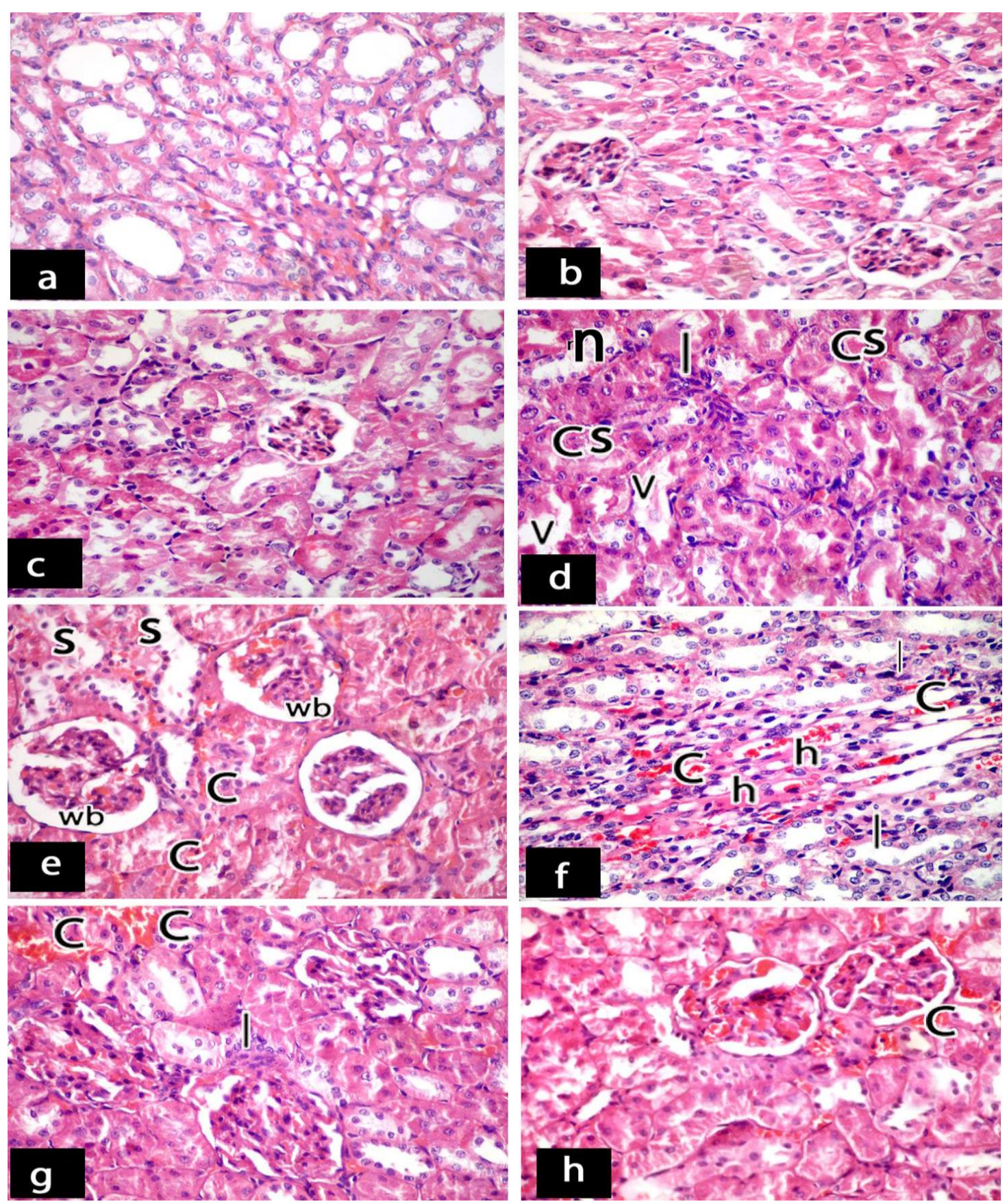

Figure (3): Photomicrographs of adult male albino rat's kidney: [a] from negative control group showing normal renal medulla, [b] from group III (D-penicillamine group ) showing normal renal cortex, [c] from group IV (garlic \& sylimarin group ) showing normal histological features, [d] from group $\mathrm{V}$ (lead acetate group ) showing disorganization, different degrees of cloudy swelling of epithelial cells of renal tubules (cs), vaculation (v), cellular necrosis (n) \& inflammatory cells infiltration (i), [e] from group V (lead acetate group) showing wide bowman' space (wb), sloughing of glomerular and tubular epithelium (s) \& congestion of the cortex ( c), [f] from group V ( lead acetate) showing congestion (c), inflammatory cells infiltration (i) and homogenous acidophilic materials (h), [g] from group VI ( lead acetate and D-penicillamine group ) showing congestion (c) \& moderate cellular infiltration (i) [h] from group VII (lead acetate and garlic + sylimarin group ) showing some congestion (c) (H\&E X 400).

\section{Discussion}

Lead belongs to the group of metals, which do not play a significant role in metabolic processes, but interfere with a variety of body functions. It is one of the most toxic environmental pollutants; even minimal doses of lead can cause serious dysfunctions of cellular metabolism prior to constitutional symptoms
(Kaczor et al., 2013; Li et al., 2015). Matović et al. (2015) stated that particularly the kidneys are among the most prominent target organs after long-term exposure to lead. 
In the present study, administration of lead acetate to rats in a dose of $20 \mathrm{mg} / \mathrm{kg} /$ day for 3 months produced significant increase of BLL, KLL \& ULL when compared to the control groups. These significant changes can be explained by Flora et al. (2006) stated that the absorbed $\mathrm{Pb}$ is conjugated in the liver and passed to the kidney, where a small quantity is excreted in urine and the rest accumulates in various body organs and affects many biological activities at the molecular, cellular and inter-cellular levels. Zheng et al. (2011) mentioned that determination of $\mathrm{Pb}$ in urine is considered to reflect $\mathrm{Pb}$ that has diffused from plasma and is excreted through the kidney. In addition, Grandjean and Herz (2015) stated that past and cumulated $\mathrm{Pb}$ exposure and its risk are most often monitored by $\mathrm{Pb}$ in blood and urine.

For the BLL, it showed significant increases that exceeded $111 \mathrm{ug} / \mathrm{dL}$ in the current study. Zhang et al. (2015) reported that as a result of environmental pollution, the normal reference range for blood $\mathrm{Pb}$ is $<10 \mu \mathrm{g} / \mathrm{dL}$. Many reviews stated that BLL as low as 2 $\mu \mathrm{g} / \mathrm{dL}$ can cause adverse health effects to multiple organ systems including renal one (Fadrowski et al., 2010; Liu et al., 2012).

Kidney lead level in this study significantly increased when compared to the level in the control rats. This can be explained by Guimarães et al. (2012); who stated that among the soft tissues, liver and kidneys show substantially higher lead concentrations. These organs play a vital part in the detoxification and metabolism of toxic substances. Sabath and RoblesOsoriol (2013) stated that the kidney serves as a major organ of $\mathrm{Pb}$ excretion and as a site of accumulation, as well as target organ of $\mathrm{Pb}$ toxicity and are under risk of damage due to the oxidative reaction of lead.

The previous biochemical finding of accumulated lead in the kidney is supported by the histopathological changes observed in rat kidneys of the current study. This is similar to the study of Guimarães et al. (2012) who found that lead intoxication caused proximal tubular dysfunction or irreversible nephropathy, where these changes depended on the exposure regimens.

The sub-acute intra-peritoneal administration of $10 \mathrm{mg} / \mathrm{kg} / \mathrm{day}$ of lead acetate for 15 days in the study of Minerva et al. (2013) induced toxic levels of lead in the blood and caused renal toxicity (pathological and functional). Histological changes observed in kidneys of treated rats included tubular necrosis, epithelial degeneration, tubular dilatation, and swelling. Proximal tubules lost their characteristic appearance and appeared irregular, deformed, and some epithelial cells of proximal tubules lacked brush borders.

The observed kidney findings are in agreement also with the findings of many other studies (Liu et al.; Wang et al.; Abdel Moneim et al., 2010; Binkowski et al., 2013). Moreover, Solidum (2014) reported that Lead is hard to biodegrade, once accumulated in the biologic system it leads to system deficits.

The non significant change in blood urea and serum creatinine which observed after lead administration in the present study passes in agreement with cohort study of Weaver et al. (2009) in which higher lead dose was associated with lower serum creatinine in exposed lead workers. This can be explained according to Onopiuk et al. (2015) who stated that, common indicators of renal function lack necessary sensitivity and specificity. Moreover Wasung et al. (2015) stated that serum creatinine is limited as a marker of renal dysfunction and may be inaccurate in several situations and new sensitive biomarkers are needed in order to facilitate early diagnosis, guide interventions and monitor kidney disease progression. From the pathological point of view Galarreta et al. (2014) mentioned that renal parenchymal injury may begin early long before sufficient glomeruli and tubules have been destroyed to provoke a decline in glomerular filtration rate.

Regarding the mechanism of the histopathological changes occurred in the kidney, it can be explained by many studies showed that leadinduced kidney injury is associated with a production of ROS, thus inducing oxidative stress; excito-toxicity and DNA damage (Dai et al., 2010; Liu et al., 2012; gargouri et al., 2013). The fact that the kidney organ is rich in mitochondria indicates that it is highly vulnerable to damage caused by oxidative stress (Sureshbabu et al., 2015).

Similar mechanism of toxicity has been proposed by Baranowska-Bosiacka et al. (2012) for the effect of Pb-exposure on blood, Li et al. (2015) for the gonadotoxic and spermiotoxic effects of lead and by Karamian et al. (2015) during investigation of the neurotoxicity of lead in albino rats, all were through the generation of excessive amount of ROS and alteration of antioxidant defense systems in animals, therefore it has been suggested that $\mathrm{Pb}$-induced oxidative stress contributes to the pathogenesis of lead poisoning by disrupting the pro-/antioxidant. This proposed mechanism can explain the significant alterations in the levels of erythrocyte MDA and blood GSH-Px levels which occurred in the current study and passes in agree with El-Sayed et al. (2015); Roy et al. (2015)

In the present study, lead-exposed rats treated with D-penicillamine for 1 month showed significant drop in BLL and KLL with significant increase in ULL when compared to lead- treated rats. Also, Dpenicillamine led to decrease in MDA and increase in GSA-Px levels with great improvement in the histopathological structure of the kidney tissue. These findings are in agree with Blanusa et al. (2005); Kianoush et al. (2012); Sisombath et al. (2014) reported that D-penicillamine which has the ability to bind lead and facilitate its excretion from the body is the old-established well-known antidote for the treatment of lead poisoning.

However the consequence of long-term Dpenicillamine treatment is associated with numerous side effects such as seizures, myasthenia gravis, polymyositis, systemic lupus erythematosus, degenerative elastosis, membranous glomerulonephritis and pemphigus (Roy et al., 2011; Poulas et al., 2012; Koraishy et al., 2013; Rahimi et 
al., 2014; Wang et al., 2015). This prompted us to search for more effective and safer treatment strategies that could replace D-penicillamine therapy.

In the present study, lead-exposed rats treated with a combination of garlic and silymarin for 1 month produced significant drop in BLL and KLL when compared to lead- treated rats. At the same time, the combination of garlic and silymarin showed more significant improvement in BLL and KLL than Dpenicillamine treated group. These findings were supported by increased ULL and decreased MDA level in the combined garlic and silymarin treated group compared to D-penicillamine treated group. Also, this combination led to significant improvement in the histopathological structure of the kidney tissue better than D-penicillamine has done. The observed curative effect of combined garlic and sylimarin on lead iduced nephrotoxicity and oxidative stress is supported by Ramirez-Garcia et al. (2015) who stated that various renal damages induced by lead poisoning can be reduced by antioxidant agents and Sabiu et al. (2015) stated that timely intervention with exogenous antioxidants augments the cellular defense system to prevent free radicals oxidative damage on cellular macromolecules.

Regarding the effect of garlic on leadinduced nephrotoxicity, it has been known that garlic, is a source of many different sulphuric compounds, which partially share metabolic pathways with phytochelatins, employing cysteine as a basic precursor for the synthesis of phytochelatin, thiosulphinate and sulphoxide (Soudek et al., 2011). Aslani et al. (2010) showed that blood and tissue lead concentrations in mice are reduced when they are treated simultaneously with oral allicin and DMSA, where they proposed that allicin acts as a chelating agent in the treatment of lead poisoning. Therefore, it is presumable that garlic ingredients (allicin or alliin) through their biologically active agents, such as thiosulfinate or amino functional groups, act through similar mechanisms as those of chelators, like penicillamine, to facilitate the excretion of lead from the body. In the study of Kianoush et al. (2012) who compared the therapeutic effects of garlic and Dpenicillamine in patients with chronic occupational lead poisoning, they found out that garlic was safer clinically and as effective as D-penicillamine.

In the present study the concomitant administration of silymarin extract to that of garlic caused a combined antioxidant effect led to improvement in the stress condition evoked by lead administrated to the rats. This was reflected in the significant decrease in MDA and increase in GSA-Px levels. Silymarin administration has been proved by Mannem (2014) to cause a recovered level of GSH when compared to lead-treated rats. Many studies proved that silymarin has the potential to attenuate the effect of nephrotoxic chemicals due to its antiinflammatory, antioxidant and anti-apoptotic properties (Dashti-Khavidaki et al., 2012; Hashmi et al., 2013; Gad and El-Maddawy, 2014; Hamza and AlHarbi, 2015). Sabiu et al. (2015) mentioned that in drug- and chemically-induced oxidative stress, silymarin has been reported as the primary therapeutic modality of choice.

To explain the better curative effect offered by the combined garlic \& silymarin extracts, research findings have suggested that administration of various antioxidants can prevent or subdue various toxic effects of lead and generation of oxidative stress in particular, where an antioxidant can prevent lead toxicity in three ways (Antonio-Garcia \& MassóGonzález, 2008):

1. By inactivating the generated ROS at molecular level, thereby terminating the radical chain reaction (chain breaking).

2. By maintaining the lead in a redox state, which leads to its incompetency to reduce molecular oxygen.

3. By chelating the lead ion and preventing further formation of ROS.

\section{Conclusions}

This study demonstrates that a combination of garlic and sylimarin has potent curative effects against $\mathrm{Pb}$ induced nephrotoxicity by modulating the antioxidant pathway in rat kidney through inhibiting ROS generation and increasing kidney GSH level. Treatment with combination of garlic and sylimarin also decreased the kidney $\mathrm{Pb}$ concentrations in rats and increased urinary excretion of lead. Moreover, Combination of garlic and sylimarin offered better curative effect than D-penicillamine.

\section{Recommendations}

It is recommended to control the population exposure to the lead and find a sensitive blood or urinary marker for early detection of kidney damage. In addition further studies are needed for the use of a combination of garlic and sylimarin and effectively replace D-penicillamine in the treatment of lead toxicities.

\section{Acknowledgment}

Sincere appreciation and deep gratitude to Professor Dr Iman A. El-Khishin the Project Manager and to the team members of the Project. Special thanks and sincere appreciation to Professor Dr Samia Salah Hafez, Prof. of Pharmacognesy, Faculty of PharmacyZagazig University, for her accurate and kind help and support in performing garlic \& sylimarin extraction. Great thanks to Dr Mona Gomaa, Lecturer of Histology, Faculty of Medicine- Zagazig University for her great help in reading histopathological results.

\section{References}

Aaseth J., Skaug M.A, Cao Y. and Andersen O. (2015): Chelation in metal intoxicationPrinciples and paradigms. J Trace Elem. Med. Biol.; 31: 260-266.

Abdel Moniem A.E., Dkhil M.A., and Al-Quraishy S. (2010): Protective role of flaxseed oil against lead acetate induced oxidative stress in testes of adult rats. African J. Biotech.; 9 (42): 7216-7223.

Al-Rudainy L.A. (2010): Blood lead level among fuel station workers. Oman Med J.; 25(3): 208211. 
Anjum M.R., Sainath S.B., Suneetha Y., and Reddy P.S. (2011): Lead acetate induced reproductive and paternal mediated developmental toxicity in rats. Ecotoxicol. Environ. Safety; 74: 793-799.

Antonio-García M.T. and Massó-González E.L. (2008): Toxic effects of perinatal lead exposure on the brain of rats: Involvement of oxidative stress and the beneficial role of antioxidants. Food Chem. Toxicol.; 46: 20892095.

AOAC. (1990): Association of Official Analytical Chemists. Official Methods of Analysis, 15 th ed., Arlington, Virginia, USA, P. 247.

Aslani M.R.; Najarnezhad V. and Mohri M. (2010): "Individual and combined effect of meso-2,3dimercaptosuccinic acid and allicin on blood and tissue lead content in mice". Planta Medical; 76:241-4.

Bancroft, G.D. and Steven, S.A. (2002): Theory and practice of histochemical technique, By Stewart $\mathrm{J}$ and Edward B. Edinburgh, London, Melbourne and new Youk: $24^{\text {th }}$ edition, Churcull, Livingston, PP. 65-72.

Baranowska-Bosiacka I., Gutowska I., Marchlewicz M. et al. (2012): Environmental toxicants: Lead and mercury. J. Ped. Health Care; 26: 213-215.

Behmke S., Fallon J., Duerr A.E. et al. (2015): Chronic lead exposure is epidemic in obligate scavenger populations in eastern North America. Environ. Inter., 79: 51-55.

Bi X., Li Z., Sun G. et al. (2015): In vitro bioaccessibility of lead in surface dust and implications for human exposure: A comparative study between industrial area and urban district. J Hazard. Mater. ; 297:191-197.

Binkowski L.J, Sawicka-Kapusta K., Szarek J. et al. (2013): Histopathology of liver and kidneys of wild living Mallards Anas platyrhynchos and Coots Fulica atra with considerable concentrations of lead and cadmium. Sci. Total Environ.; 450: 326-333.

Boisa N., Elom N., Dean J.R et al. (2014): Development and application of an inhalation bioaccessibility method (IBM) for lead in the PM10 size fraction of soil. Environ. Intern. ; 70: 132-142.

Blanusa M.; Varnai V.M.; Piasek M. and Kostial K. (2005): "Chelators as antidotes of metal toxicity: therapeutic and experimental aspects". Current Med. Chem.; 12: 2771-94.

Brown M.J and Margolis S. (2012): Lead in drinking water and human blood lead levels in the United States. MMWR; 61: 1-9.

Cao S., Duan X., Zhao X. et al. (2015): Levels and source apportionment of children's lead exposure: Could urinary lead be used to identify the levels and sources of children's lead pollution?. Environ. Pollu.; 199: 18-25.
Dai W., Fu L., Du H. et al. (2010): Effects of montmorillonite on $\mathrm{Pb}$ accumulation oxidative stress, and DNA damage in Tilapia (Oreochromis niloticus) exposed to dietary Pb. Biol. Trace Elem. Res., 136: 71-78.

Dashti-Khavidaki S.; Shahbazi F.; Khalili H. and Lessan-Pezeshki M. (2012): "Potential renoprotective effects of silymarin against nephrotoxic drugs: a review of literature". J. Pharmacol. Pharmacog. Sci.; 15: 112-123.

El-Sayed M.F., Abdel-Ghafar S.K., Adly M.A. et al. (2015): The ameliorative effects of DMSA and some vitamins against toxicity induced by lead in the testes of albino rats. II. J Basic Appl. Zoo., 71: 60-65.

Fadrowski J.J., Navas-Acien A., Tellez-Plaza M. et al. (2010): Blood lead level and kidney function in US adolescents: the third national health and nutrition examination survey. Arch. Intern. Med.; 170 (1): 75-82.

Flora S.J.S.; Flora G. and Saxena G. (2006): "Environmental occurrence, health effects and management of lead poisoning. (In: Jose, S. C, Jose, S., eds. Lead. Amsterdam: Elsevier Science B.V.). pp. 158-228.

Flora, S.J.S and Pauchauri, V. (2010): Chelation in metal intoxication. Int J Environ Res Public Health.; 7(7): 2745-2788.

Gad S.B. and El-Maddawy Z.K. (2014): "Silymarin improves pancreatic endocrine function in rats". Pakistani Vet. J.; 34: 214-218.

Galarreta C.I., Grantham J.J., Forbes M.S. et al. (2014): Tubular Obstruction Leads to Progressive Proximal Tubular Injury and Atubular Glomeruli in Polycystic Kidney Disease. American J. Pathol.; 184: 19571966.

García-Lestón J., Méndez J., Pásaro E. and Laffon B (2010): Genotoxic effects of lead: an updated review. Environ Int.; 36(6):623-36.

Gargouri M.; Christian M.;Xavier D.; et al. (2013): Cytoprotective and antioxidant effects of the edible halophyte Sarcocornia perennis L. (swampfire) against lead-induced toxicity in renal cells Ecotoxicol. Environ. Safety; 95: 44-51.

Godwill E.A, Jane I.C, Scholastica I.U. et al.(2015): Determination of some soft drink constituents and contamination by some heavy metals in Nigeria. Toxicol. Reports, 2: 384-390.

Golalipour M.J., Roshandel D., Roshandel G., et al., (2007): Effect of lead intoxication and Dpenicillamine treatment on hematological indices in rats. Int J. Morphol; 25(4):717722.

Grandjean P. and Herz K.T.(2015): Trace elements as paradigms of developmental neurotoxicants: Lead, methylmercury and arsenic. J Trace Elem. Med. Biol., 31: 130-134. 
Guimarães D., Carvalho M.L., Geraldes V., et al. (2012): Lead in liver and kidney of exposed rats: Aging accumulation study. J. Trace Elem. Med. Biol.; 26: 285-290.

Hamza R.Z. and Al-Harbi M.S. (2015): Silymarin and Nigella sativa extract ameliorate paracetamol induced oxidative stress and renal dysfunction in male mice. Asian Pacific J. Trop. Dis.; 5: S169-S174.

Hashmi N.; Muhammad F.; Javed I.; et al. (2013): "Nephroprotective effects of Ficus religiosa linn (peepal plant) stem bark against isoniazid and rifampicin induced nephrotoxicity in albino rabbits". Pakistani Vet. J.; 33: 330-334.

Henry, R. J. (1974): Clinical chemistry. Principles and Techniques. 2nd Edition. Harper and Row.

Instito' ris L., Siroki O., De'si I., et al., (1999): Immunotoxicological examination of repeated dose combined exposure by dimethotrexate and two heavy metals in rats. Hum. Exp. Toxicol.; 18 (2):88-94.

Jain A., Yadav A., Bozhkov A.I., et al. (2011): Therapeutic efficacy of silymarin and naringenin in reducing arsenic-induced hepatic damage in young rats. Ecotoxicol. Environ. Safety 74: 607-614.

Johnson, M.D. (2007): The Rats. In: Animal Models of Toxicology, Gad, S.C. (eds.), $2^{\text {nd }}$ ed., CRC Press, Taylor \& Francis Group, LLC, Boca, Raton, London, New York, Ch., 3, P. 187188.

Kaczor M., Sura P., Bronowicka-Adamska P. And Wróbel M. (2013): Exposure to lead in water and cysteine non-oxidative metabolism in Pelophylax ridibundus tissues. Aqua. Toxicol.; 127: 72-77.

Karamian R., Komaki A., Salehi I. et al. (2015): Vitamin C reverses lead-induced deficits in hippocampal synaptic plasticity in rats. Brain Res. Bull., 116: 7-15.

Kayaalti Z., Kaya-Akyüzlü D., Söylemez E. and Söylemezoğlu T.(2015): Maternal hemochromatosis gene H63D singlenucleotide polymorphism and lead levels of placental tissue, maternal and umbilical cord blood. Environ. Res.; 140: 456-461.

Kianoush S.; Balali-Mood M.; Reza S.; et al. (2012): "Comparison of Therapeutic Effects of Garlic and D-Penicillamine in Patients with Chronic Occupational Lead". Poisoning Basic \& Clin Pharmacol Toxicol.; 110: 476-481.

Kurien B.T., Nancy E.E. and Scofield R.H (2004): Experimental animal urine collection: a review. Lab Animals; 38: 333- 361.

Koraishy F.M., Cohen R.A., Israel G.M. and Dahl N.K. (2013): Cystic Kidney Disease in a Patient with Systemic Toxicity from Longterm d-Penicillamine Use. American J Kidney Dis, 62: 806-809.
Lee Y.W. and Kim C. (2012): Remediation of leadcontaminated soil with non-toxic biodegradable natural ligands extracted from soybean. Environ Technol; 33(19-21):24152420.

Li N., Hour Y-h., Ma D-d. et al. (2015): Lead accumulation, oxidative damage and histopathological alteration in testes and accessory glands of freshwater crab, Sinopotamon henanense, induced by acute lead exposure. Ecotoxicol. Environ. Safety, 117: 20-27.

Liu C-M., Ma J-Q. and Sun Y-Z. (2010): Quercetin protects the rat kidney against oxidative stress-mediated DNA damage and apoptosis induced by lead. Environ. Toxicol. Pharmacol.; 30: 264-271.

Liu C-M., Ma J-Q. and Sun Y-Z. (2012): Puerarin protects rat kidney from lead-induced apoptosis by modulating the PI3K/Akt/eNOS pathway. Toxicol Applied Pharmacol.; 258: 330-342.

Mannem P. (2014): Lead Toxicity on Kidney Antioxidant Enzymes with the Protective Role of Ginger in Male Albino Rats. Int. J Biol. Sci.; 3: $2277-8179$.

Matović V., Buha A., Đukić-Ćosić D. and Bulat Z. (2015): Insight into the oxidative stress induced by lead and/or cadmium in blood, liver and kidneys. Food Chem. Toxicol.; 78:130-140.

Mielke H.W., Covington T.P., Mielke P.W., et al. (2013): Environmental and health disparities in residential communities of New Orleans: The need for soil lead intervention to advance primary prevention. Environ Inter.; 51: 7381.

Miller D.T., Paschal D.C., Gunter E.W., et al., (1987): Determination of lead in blood using electrothermal atomization atomic absorption spectrometry with a L'vov platform and matrix modifier. Analyst; 112: 1701- 1704.

Minerva M-A., Gonzalo R-G., Silvia G-G., et al. (2013): Melatonin attenuates the effects of sub-acute administration of lead on kidneys in rats without altering the lead-induced reduction in nitric oxide. $\mathrm{J}$ Trace Elem. Med. Biol.; 27: 364-369.

Mohammadi A. and Oshaghi E.A. (2014): Effect of garlic on lipid profile and expression of LXR alpha in intestine and liver of hypercholesterolemic mice. J Diabetes Metab Disord,; 13: 20-29.

Monnot A.D., Christian W.V., Abramson M.M. and Follansbee M.H. (2015): An exposure and health risk assessment of lead $(\mathrm{Pb})$ in lipstick. Food Chem. Toxicol.; 80: 253-260.

Oliveira D.R., Schaffer L.F., Busanello A., et al. (2015): Silymarin has antioxidant potential and changes the activity of $\mathrm{Na}+\mathrm{K}+-\mathrm{ATPase}$ and monoamine oxidase in vitro. Ind. Crops Prod.; 70: 347-355. 
Onopiuk A., Tokarzewicz A. and Gorodkiewicz E. (2015): Cystatin C: Kidney Function Biomarker. Advances Clin. Chem.; 68: 5769.

Padilha R.Q., Riera R., Átallah A.N. (2011): Homeopathic Plumbum metallicum for lead poisoning: a randomized clinical trial. Homeopathy; 100(3):116-21.

Piadé J-J., Jaccard G., Dolka C. et al. (2015): Differences in cadmium transfer from tobacco to cigarette smoke, compared to arsenic or lead. Toxicol. Reports, 2: 12-26.

Pleban, P.A.; Munyani, A. and Beachum, J. (1982): Determination of selenium concentration and glutathione peroxidise activity in plasma and erythrocytes. Clin. Chem.; 2(2):311316.

Polyak, S.J.; Morishima, C.; Shuhart, M.C.; et al. (2007): Inhibition of $\mathrm{T}$-cell inflammatory cytokines, hepatocytes NF-KB signaling, and HCV infection by standardized silymarin. Gastroenterol.; 132(5):1925-1936.

Poulas K., Koutsouraki E., Kordas G., Kokla A., Tzartos S.J. (2012): Anti-MuSK- and antiAChR-positive myasthenia gravis induced by d-penicillamine. J Neuroimmunol.; 250: 9498.

Rahimi N., Sadeghzadeh M., Javadi-Paydar M. et al. (2014): Effects of d-penicillamine on pentylenetetrazole-induced seizures in mice: Involvement of nitric oxide/NMDA pathways. Epilep. Behav.; 39: 42-47.

Ramirez-Garcia G., Martinez-Alfaro M., GutierrezGranados S., et al.(2015): Electrochemical Assessment of Possible Melatonin Effect On Nitric Oxide Production From Kidneys Of Sub-Acute Lead Treated Rats. Electrochim. Acta, 166: 88-92.

Roy D.N., Sen G., Chowdhury K.D and Biswas T. (2011): Combination therapy with andrographolide and d-penicillamine enhanced therapeutic advantage over monotherapy with d-penicillamine in attenuating fibrogenic response and cell death in the periportal zone of liver in rats during copper toxicosis. Toxicol Applied Pharmacol.; 250: 54-68.

Roy A., Queirolo E., Peregalli F. et al.(2015): Association of blood lead levels with urinary F2-8 $\alpha$ isoprostane and 8-hydroxy-2-deoxyguanosine concentrations in first-grade Uruguayan children. Environ. Res.; 140: 127 135.

Sabath E. and Robles-Osorio M.L. (2013): Renal health and the environment: heavy metal nephrotoxicity. Nefrologia, 32: 279-286.

Sabiu S., Sunmonu T.O., Ajani E.O. and Ajiboye T.O. (2015): Combined administration of silymarin and vitamin $\mathrm{C}$ stalls acetaminophen-mediated hepatic oxidative insults in Wistar rats. Revista Brasileira de Farmacognosia, 25: 29-34.
Schäfer G. and Kaschula C.H. (2014): The immunomodulation and anti-inflammatory effects of garlic organosulfur compounds in cancer chemoprevention. Antican. Agents Med Chem, 14 :. 233-240.

Shaarawy S.M., Tohamy A.A., Elgendy S.M., et al., (2009): Protective Effects of Garlic and Silymarin on NDEA-Induced Rat's Hepatotoxicity; Int J Biol Sci. 5(6): 549-557.

Sisombath N.S., Jalilehvand F., Schell A.C. and Wu Q. (2014): Lead(II) binding to the chelating agent D-penicillamine in aqueous solution. Inorg Chem.; 53: 12459-68.

Skerfving S., Löfmark L., Lundh T. et al. (2015): Late effects of low blood lead concentrations in children on school performance and cognitive functions. NeuroToxicology, 49: 114-120.

Solidum J.N. (2014): Heavy Metal Lead in Filipino Staple Food as Studied in Metro Manila, Philippines. APCBEE Procedia, 9: 102-107.

Soto C., Pérez J., García V., Uría E., Vadillo M., Raya L. (2010): Effect of silymarin on kidneys of rats suffering from alloxaninduced diabetes mellitus. Phytomedicine, 17: 1090-1094.

Soudek P., Šárka Petrov S. And Vaněk T. (2011): Heavy metal uptake and stress responses of hydroponically cultivated garlic (Allium sativum L) Environ Experim Botany 74: 289-295.

Sureshbabu A., Ryter S.W. and Choi M.E. (2015): Oxidative stress and autophagy: Crucial modulators of kidney injury. Redox Biology, 4:208-214.

Szymańska-Chabowska A., Łaczmański L., Jędrychowska I. et al. (2015): The relationship between selected VDR, HFE and ALAD gene polymorphisms and several basic toxicological parameters among persons occupationally exposed to lead. Toxicol.; 334: 12-21.

Vaid M., Prasad R., Singh T., et al. (2013): Silymarin inhibits ultraviolet radiationinduced immune suppression through DNA repair-dependent activation of dendritic cells and stimulation of effector $\mathrm{T}$ cells. Biochem Pharmacol; 85(8):1066-1076.

Wang L., Wang Z. and Liu J. (2010): Protective effect of $\mathrm{N}$-acetylcysteine on experimental chronic lead nephrotoxicity in immature female rats. Hum. Exp. Toxicol.; 29 : 581-591.

Wang D., Liang J., Xu J. and Chen L. (2015): Effective treatment of d-penicillamine induced elastosis perforans serpiginosa with ALA-PDT. Photodiag. Photody. Ther.; 12: 140-142.

Wasung M.E, Chawla L.S and Madero M. (2015): Biomarkers of renal function, which and when?. Clinica Chimica Acta; 438: 350-357. 
Weaver V.M., Griswold M., Todd A.C., et al. (2009): Longitudinal associations between lead dose and renal function in lead workers. Environ Res.; 109: 101-107.

Yang G., Zhao Y., Feng N. et al. (2015): Improved dissolution and bioavailability of silymarin delivered by a solid dispersion prepared using supercritical fluids. Asian J. Pharmaceu. Sci.; 10: 194-202.

Yoshioka T., Kawada K., Shimada T., Mori M. (1979): Lipid peroxidation in maternal and cord blood and protective mechanism against activated-oxygen toxicity in the blood. Am J Obstet Gynecol.;135(3):372-6.
Zaidi S.K., Ansari S.A., Ashraf G.M. et al. (2015): Reno-protective effect of garlic extract against immobilization stress induced changes in rats. Asian Pacific J. Trop. Biomed.; 5: 364-369.

Zhang L-L., Lu L., Pan Y-J., et al. (2015): Baseline blood levels of manganese, lead, cadmium, copper, and zinc in residents of Beijing suburb. Environ. Res.; 140 : 10-17.

Zheng G., Tian L., , Liang Y., et al. (2011): $\delta$ Aminolevulinic acid dehydratase genotype predicts toxic effects of lead on workers' peripheral nervous system. Neuro Toxicol.; 32: 374-382.

\section{الملخص العربى}

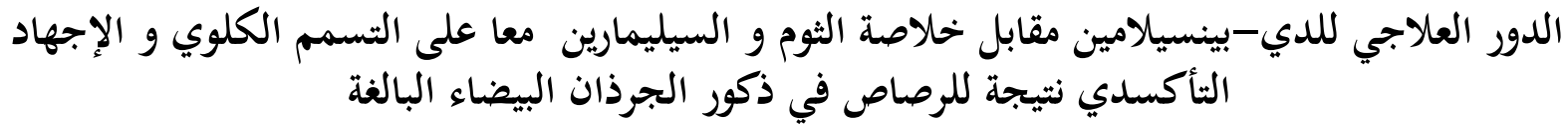

\section{أمل محمد عبد الخالق و نيرمين عطية إبراهيم'}

مازال التسمم بالرصاص يمثل مشكلة صحية عالمية خاصة في البلدان النامية. لقد استخدم الرصاص على نطاق واسع منذ سنوات بعيدة و سوف يستمر استخدامه في المستقبل.

يهدف هذا البحث الي مقارنة الدور العلاجي للدي-بنينيسلامين مقابل خحلاصة الثوم و السيليمارين معا على التسمم الكلوي والإجهاد

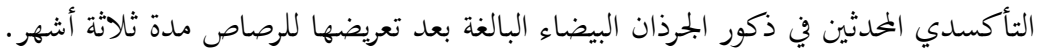

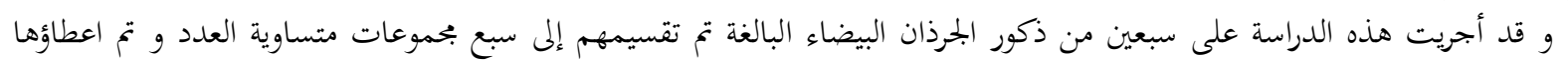

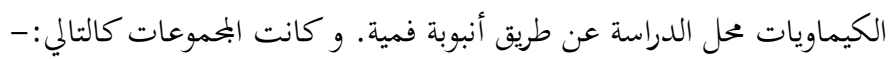

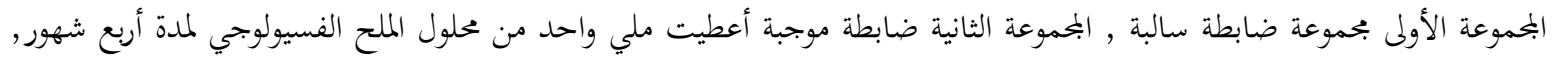

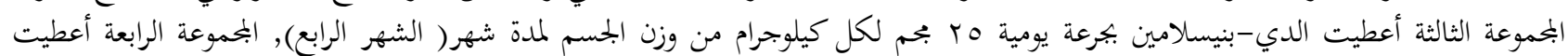

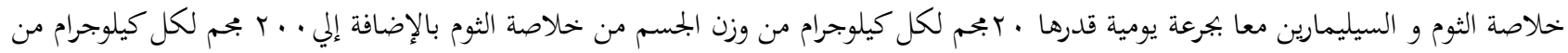

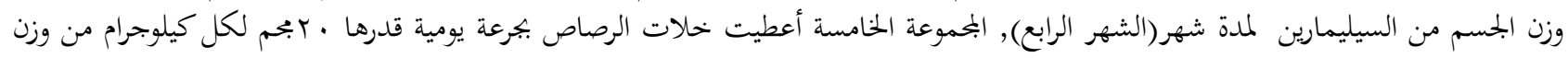

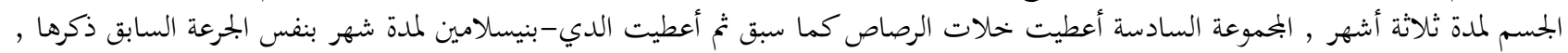

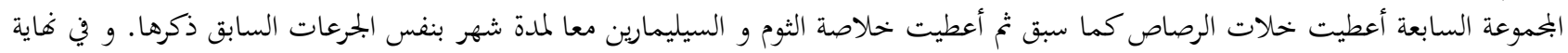

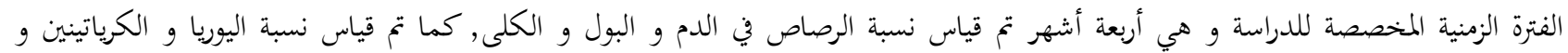

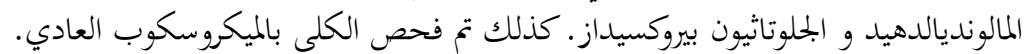

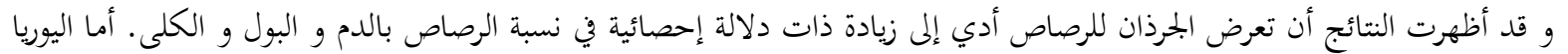

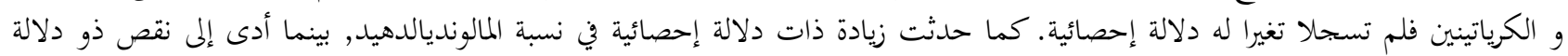

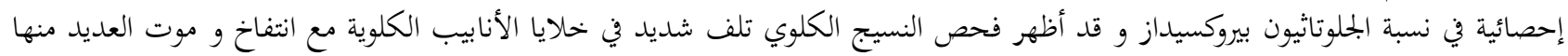

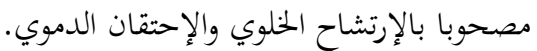

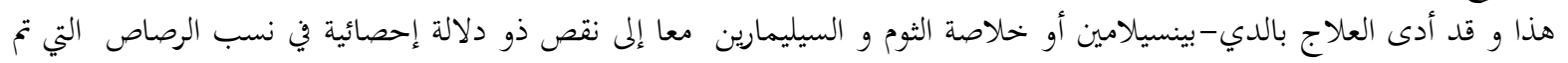

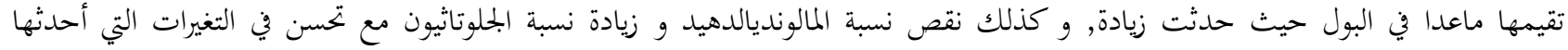

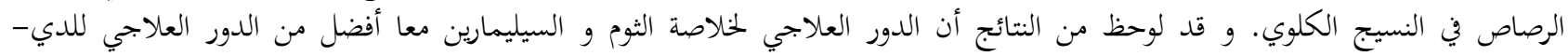
بنيسلامين.

و بناء على النتائج المستخلصة من هذه الدراسة يوصي بالتحكم في التعرض للرصاص و البحث عن دلائل في الدم أو البول ذات

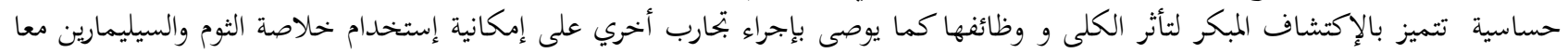
كعلاج فعال للأثنار السمية للرصاص.

ا قسم الطب الثرعي والسموم الإكلينيكية - كلية الطب - جامعة الزقازيق. 